\title{
Human Resource Information Systems: A Review in the Adoption of Open Source
}

\author{
Sharon Pande, PhD. \\ Area Chairperson and Associate Professor - \\ Human Resources and Behavioral Sciences \\ School of Business Management, N.M.I.M.S. \\ University, Mumbai, India
}

\author{
Neville Gomes \\ Co-founder, Simplified Business Solutions. \\ Visiting professor of e-Business and e-HRM, \\ Mumbai Educational Trust, Mumbai, India
}

\begin{abstract}
The paper highlights the use and importance of an Open Source Software for Human Resource Information Systems. Open source software development projects are Internet-based communities of software developers who voluntarily collaborate to develop software that they or their workplace may require. They present a challenging, novel and successful alternative to conventional models and also offer opportunities for a view into their detailed inner workings. The project operates by way of detailed and time-stamped logs of most interactions among community members and of project outputs are generated in an automatic fashion. This makes open source software projects important as research sites for many types of studies. The authors have also drawn up a mind map of Open Source Model for Human Resource Information Systems and a Model of Adoption of an Open Source Human Resource Information System. It further discusses various open source software in the area on Human Resources and the important aspect of open source HRIS and cloud hosting with SMEs
\end{abstract}

General Terms: Human Resource Information Systems, HRIS and Open Source

Keywords: Human Resource Information Systems, Open Source, Open Source Model Adoption, Open Source Model.

\section{INTRODUCTION AND HISTORY OF OPEN SOURCE SOFTWARE}

Open source is a philosophy that stems from the concept of sharing of information on the design, composition of a product, service or experience. The basis for sharing would lead to a better product, service or experience and the widespread adoption of it too. The term or label 'Open source' was coined during a strategy session held on Feburary $3^{\text {rd }}, 1998$ in Palo Alto, California which was attended by Todd Anderson, Chris Peterson, John Hall and Larry Augustin, Sam Ockman, Michael Tiemann, and Eric Raymond.

This movement took off in the late nineties with an alternative to the market dominated Windows platform and the fact that Linux was catching up too. Nevertheless, open source can be traced way back to mid 1960's where IBM and other companies that sold large scale commercial computers were bundled with a free software. The software came with its source code so that it could be improved and modified as and when required. Initially, the intention of distributing free software with its source code was generally due to compatibility and porting issues. Most of the software companies began to compete with the hardware manufacturer's bundled software and this however led to the proliferation of proprietary software. This meant that users were not allowed to redistribute it and the source code was not available so that consumers could modify it.

In 1991, Linus Torvalds a student of computer science at the University of Helsinki was working on operating systems. He came across the MINIX which was developed by Andrew S. Tanenbaum and found it relatively restrictive as it was licensed for educational purpose only. This encouraged him to implement his own version, which was later called the Linux kernel. The increasing market share of various vendors has lead software companies to develop business applications in the open source realm.

\section{COMMENCEMENT OF OPEN SOURCE}

In the 1970s, proprietary software - i.e. software that did not allow users to redistribute it, modify it, or access its source code - became the norm. The development of open source software was a reaction to the fact that changes or improvements could not be made to proprietary software by other developers or users. The open source movement started with Richard Stallman's general public license model (in the 1980s), which holds that software should be freely modifiable, with the condition that if you make improvements to the software, you must put the improvements back in the open source community. The rationale for the open source movement is that a larger group of programmers not concerned with proprietary ownership will produce a better product.

The adoption of open systems denotes a major paradigm shift in information systems, development and management. It may be defined as a system, which can be modified as per the user's needs. It permits one to modify and interconnect in terms of inputs and outputs to other systems too. The premise for adoption of open systems is to ensure interoperability and quality through community contributions towards the development of the system. Open systems exist both in the software and the hardware that runs it. Such systems attempts to implement a suite of interface standards between system software/hardware, applications and the communications systems whose purpose is to enhance compatibility, interoperability, scalability and flexibility of the IT infrastructure.

An Open source software indicates that it is available under a no-fee license that permits users to download, change and improve the software and to redistribute it in modified form. The catch here is that the typical open-source licenses, products developed from the source code must also be placed in the public domain - "open" for others. Hence, this has resulted in the continuous improvement of the code in a public, collaborative manner, which is then beneficial of all those who want to use it. The larger the developer community, the quicker 
bugs are fixed and the faster such software is improved-one reason for the success of Linux. Once called "free" softwaredistributed free of royalties - open source became the common name in the 1990s, when advocates decided to market the software as an alternative to proprietary programs. At the time, an open-source web server called Apache was being adopted, this now, drives more than half of all web sites. Linux was adopted as the open-source software for many of such sites. Linux also gained ground in back-office settings requiring a great deal of computing power and multiple instances of an operating system. In today's scenario , it is hard to find an enterprise computing environment that doesn't have Apache, Linux or open-source software.

\section{WHY SHOULD COMPANIES ADOPT AN OPEN SOURCES SOFTWARE?}

Open source software development projects are Internet-based communities of software developers who voluntarily collaborate to develop software that they or their workplace may require. They present a challenging, novel and successful alternative to conventional models and also offer opportunities for a view into their detailed inner workings. The project operates by way of detailed and time-stamped logs of most interactions among community members and of project outputs are generated in an automatic fashion. This makes open source software projects important as research sites for many types of studies.

The following reasons highlight some of the advantages of Open source projects for becoming a significant economic and social phenomenon :

Complete customization: Since open source software is available along with its source code. It enables a user to tailor the software by modifying the source code as per their requirements. The requirements may be in terms of functionality to adapt to dynamic business conditions. For example, Open Bravo is an open source web based ERP system. The need may also rise to port the open source software to a different platform. This occurred when Microsoft ported the Office application to the Mac platform.

Visibility: For a developer perspective, a contribution to an open source project or an open source application initiative provide much needed exposure online to the developer's skill and creativity which in turn could lead to employment. By contributing to an open source project is an era where our decisions are aided by reviews online, it also provides the developer with peer reviews which can which can spur the developer to provide even a better code.

Quality by collaboration: Almost all open source projects are accessible online and the collaborative efforts of thousands of developers ensure that the application or system is one of continuous creation and improvement. There is also an instant feedback mechanism from the user end, which enables the developers to provide quick response solutions or bug fixing. This enabled the user to feel as a part of the creation process as well.

Not bounded to a single company: With proprietary software the risk is that if the developing company shuts shop or goes bankrupt the end users are severely affected in terms of support and updates. However, with the open source movement the application is not bound to a single organization due to the availability of its freely modifiable source code. For instance Mandriva SA a French company that produced Mandriva Linux a Linux operation system distribution acquired Edge-IT, a Paris based corporate support company. Due to uncertainty prevailing due to layoffs and the liquidation of Edge-IT, groups of former employees and community supporters forked Mandriva Linux to create Mageia Linux.

Accountability: Since open source philosophy mandates that the source code be distributed along with the object code it is open to scrutiny for quality and security issues. On the other hand proprietary software vendors compels its users to go by the vendor's word on security, compliance to standards and quality.

Support: Community support is an integral part of the open source movement. Google has leveraged this too. It acquired Android Inc. in 2005 and a team led by Andy Rubin developed a cellphone operating system based on the open source Linux kernel. The android open source project led by Google has large support community online, which is powered by support groups and project discussions.

Open source projects do not pay participants for their help and those who download open source software are free riders and only a small proportion contribute to a project by developing a code or contribution in some other areas. Other major sources of motivation include intrinsic rewards such as personal interest and enthusiasm, learning and enjoyment from programming. Most contributors are experienced, professional programmers. Some act as independent individuals, others are employees of organizations that support their participation (Lakhani and Wolf 2001)

\section{OPEN SOURCE SOFTWARE ADOPTION}

An interesting case of technology standards selection involves the choice between proprietary and open source software. Open source software has gained a great deal of attention recently, as numerous Internet-based applications such as Apache, Perl and Send mail have gained widespread adoption. The best-known open source software is Linux, a Unix-compatible operating system created in the early 1990 s by Finnish programmer Linus Torvalds and developed by a large community of programmers around the world.

When considering open source-based platforms, there are at least two critical variations when compared to more traditionally proprietary platforms such as those offered by Microsoft, IBM or SunMicrosystems. First, the R\&D, sales and support for the proprietary solution is the responsibility of a well defined profit-making enterprise that receives income from its products, while the open source solution uses collaborative R\&D and support in cooperation with firms whose role is far less central or defined. Second, the fundamental difference of open source software is that the source code is widely available to all and thus adopting organizations have the opportunity to modify the software to suit their own requirements. Nevertheless, very little work has been done to see how the organizational adoption of open source differs from that of other related technologies. An exception is Franke and von Hippel (2003), who surveyed the motivations of webmasters who had adopted the Apache open source web server application, showing that the more skilled users who modified the source code were most satisfied with their decision.

\section{OPEN SOURCE - HUMAN RESOURCES}

As discussed earlier, Open source means the software is free and its source code is accessible. In Human Resources, open source is in its infancy. There's an open-source HRIS- 
OrangeHRM - used by hundreds of organizations, and some under development. The software is available for performance management, and recruitment and selection and other HR functions. Exact adoption rates are unavailable but appear to be small. Many HR organizations tend to benefit from open-source software. Commercial HR software developers often use some open-source components in their products. Few vendors of HR software-as-a-service (SAAS) use open source in their hosting environments too. For example, Workday Inc. in Pleasanton, California, sells proprietary HR modules on the SAAS model and has a hosting infrastructure built entirely of open-source software including Linux and MySQL. Currently the interested lot could face several issues: few products, few distributors with proven business models and few developers too.

\subsection{A Mind Map of Open Source Model: Human Resource Information Systems}

There are various parameters both intra and extra organizational factors that lead an organization to adopt an open source HRIS.

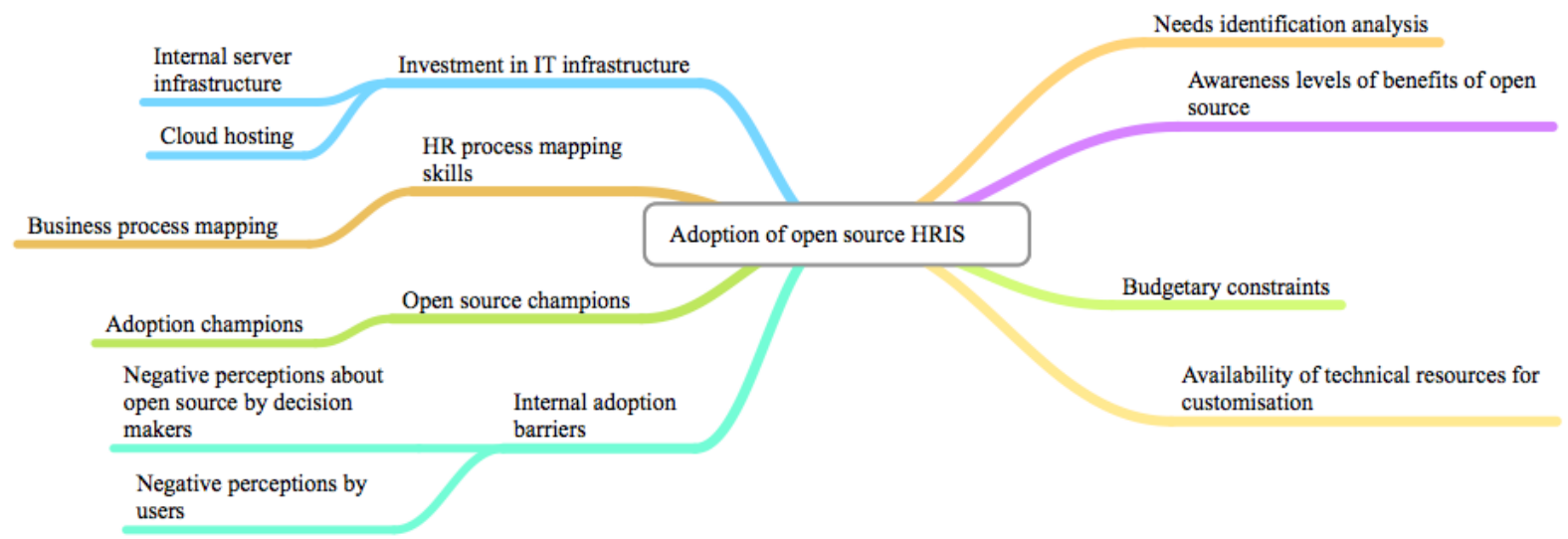

Figure No. 1: A Mind Map of Open Source Model: Human Resource Information Systems

\subsection{A Model for adoption of Open Source HRIS}

Above is a typical organizational mind map, which maps out the various factors having a direct or indirect impact on the adoption of an open source HRIS application from which the model is derived.

1. The initial phase start out with 'needs' identification for an adoption of an HRIS application. Software in its purest form is adopted as a problem solver and then enabler of more efficient business processes.

Once the needs have been identified and analyzed, the next stage would be overcoming various adoption barriers.

2. Although the benefits of using an open source system are well know in the information technology fraternity, negative perceptions about open source can be held by the decision makers at strategic management and end users who in most cases would not be from a information technology background There is a strong co-relation between dominance of proprietary business software in terms of market share and the influence of word of mouth recommendations on adoption of applications.
Another barrier to adoption is the access to technical resources with open source technology knowledge.This is essential to the successful implementation of an open source HRIS in terms of customization and support.

Most open source HRIS application are web based client-server application which entails using a server on which a web server and database server needs to be installed. Investment in a server can be an adoption barrier if the organization is working on a limited IT budget. This barrier can be mitigated however, by using HRIS on the cloud as a hosted service.

3. Most of the barriers above can be mitigated when open source champion or evangelists exists in the organization as they not only possess the requisite expertise to ensure smooth adoption of the open source HRIS application but also can work in conjunction with an external consultant.

External consultants can also play a role of a deal maker or deal breaker in organizations in making a choice of an open source or proprietary HRIS application. 


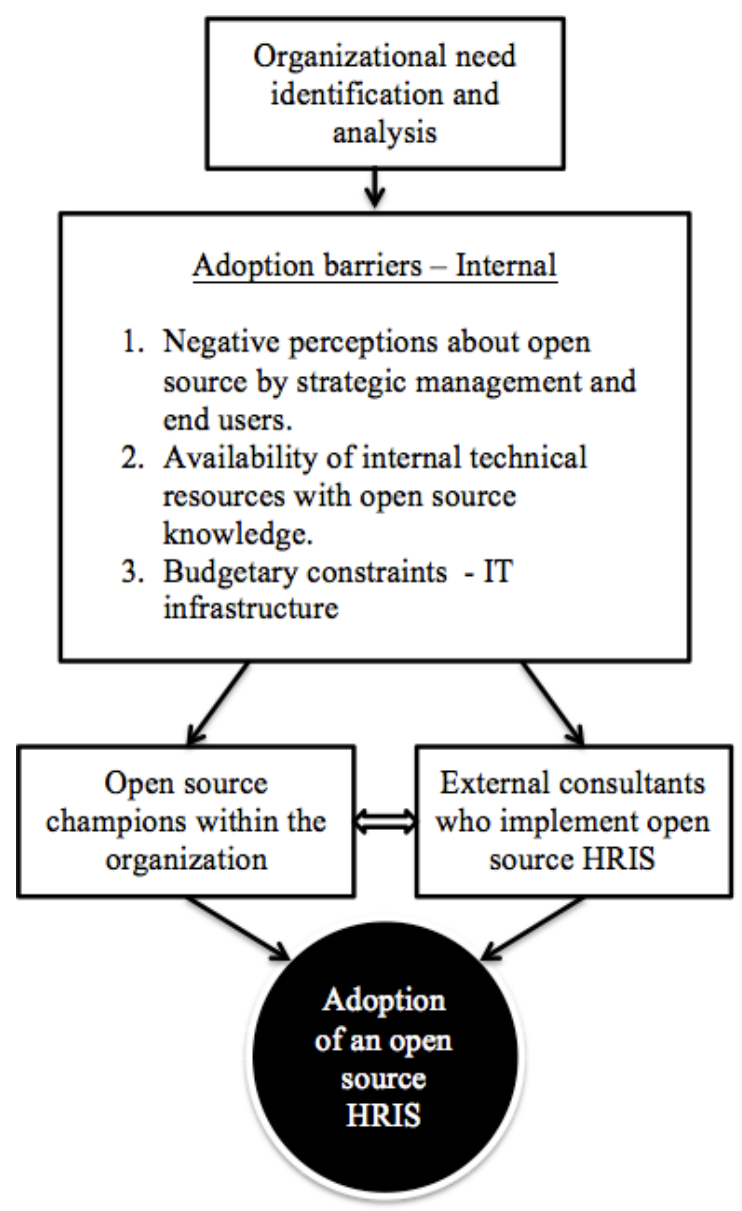

Figure No. 2: Model of Adoption of an Open Source Human Resource Information System

Some of the examples of Open Source - HR Models are:

OrangeHRM: The software has been downloaded more than 180,000 times and officials in 700 organizations identify themselves as production users in surveys, according to company founder and Chief Executive Officer Sujee Saparamadu. It has 250 customers who subscribe to its support services. Many users are in organizations with a dozen or fewer employees, and most migrate to open-source software from spreadsheets. Some of the companies have more than 2,000 employees, including some that had been using commercial software. OrangeHRM was adopted in September 2008, the IT staff downloaded and installed OrangeHRM. Loading the MySQL database has been the biggest chore, she notes. According to Ugur C. Yildiz, the founder of the project OpenHRIS is conceptually designed by HR professionals in Turkey, who still need to find programmers to write the code. He finds that commercial HRIS too costly and complicated for smaller companies. Most users run the software on their own servers, but OrangeHRM recently began a hosted model. OrangeHRM's staff of 18 includes HR process experts and software programmers, the company recently began to build an outside community of developers and HR experts to contribute to the initiative. 
Table No.1: Examples of Open Source - HR Models

\begin{tabular}{|c|c|c|}
\hline Open Source - HR & Features & HR Modules \\
\hline OrangeHRM & $\begin{array}{l}\text { Started by OrangeHRM Inc. based } \\
\text { out of New Jersey, USA, } \\
\text { OrangeHRM is a web based HRM } \\
\text { targeted at the small and medium } \\
\text { sized enterprises (SMEs). It offers } \\
\text { two flavors in the form of a free open } \\
\text { source solution or as a cloud based } \\
\text { (SaaS), which is paid. The open } \\
\text { source version can be installed on } \\
\text { Windows as well the Linux platform. }\end{array}$ & $\begin{array}{l}\text { Some of the modules available with the open source version are } \\
\text { - Administration } \\
\text { - PIM Module } \\
\text { - Leave Module and management } \\
\text { - Time and Attendance } \\
\text { - Employees Self Service } \\
\text { - Recruitment Module } \\
\text { - Performance Module } \\
\text { The company also offers additional add on modules at a cost } \\
\text { which include training, budgets, job and salary history, document } \\
\text { management, advanced reporting, insurance benefits, security } \\
\text { authorization, travel management and performance } 360 \text {. }\end{array}$ \\
\hline Open Applicant & $\begin{array}{l}\text { It was initially developed by } \\
\text { Originate Labs for internal use in } \\
\text { screening and hiring engineering } \\
\text { talent and eventually was released as } \\
\text { an open source project in } 2009 \text {. }\end{array}$ & $\begin{array}{l}\text { Its features include: } \\
\text { - Resume and email screening } \\
\text { - Online candidate assessment tools } \\
\text { - Grading tools } \\
\text { - Answer replay } \\
\text { - Result analytics and Report generation } \\
\text { - Resume organization } \\
\text { - Standard test libraries } \\
\text { - Custom test creation } \\
\text { - Candidate benchmarking } \\
\text { - Candidate matching }\end{array}$ \\
\hline LATRIX & $\begin{array}{l}\text { It is an HR web based support } \\
\text { application. The project is hosted at } \\
\text { sourceforge }\end{array}$ & $\begin{array}{l}\text { Some of the key features are } \\
\text { - Attendance recording } \\
\text { - Simple presence recording - barcoded id and magnetic strip } \\
\text { cards } \\
\text { - Multiple location and time-zone support } \\
\text { - Leave management } \\
\text { - Block periods for seasonal work }\end{array}$ \\
\hline TimeTrex & $\begin{array}{l}\text { It is an open source payroll and } \\
\text { attendance management system } \\
\text { developed and supported by } \\
\text { TimeTrex Payroll Services, a } \\
\text { company based in Canada. }\end{array}$ & $\begin{array}{l}\text { It four main modules are } \\
\text { - Scheduling } \\
\text { - Attendance } \\
\text { - Job costing } \\
\text { - Payroll }\end{array}$ \\
\hline ICeHRM & $\begin{array}{l}\text { Another sourceforge hosted project, } \\
\text { it is a java based open source } \\
\text { solution. It employs a rich user } \\
\text { developed with AJAX } \\
\text { (Asynchronous JavaScript and } \\
\text { XML). }\end{array}$ & $\begin{array}{l}\text { It consists of a PIM (Personnel information manager) and a leave } \\
\text { management system. The project is currently active. }\end{array}$ \\
\hline Waypoint HR & \multicolumn{2}{|c|}{$\begin{array}{l}\text { A product of HR-Fundamentals Limited based in Surrey, UK, Waypoint HR is also a web based HRM. } \\
\text { However its exists in a pre-release alpha form which is a technical preview and is provided under the } \\
\text { GPL v3 open source license. The project is hosted on http://sourceforge.net/projects/waypointhr/ . (The } \\
\text { last community update was on 19/05/2011, which leads us to believe that the project is inactive). }\end{array}$} \\
\hline
\end{tabular}




\section{Case Example}

One adopter for an independent, non profit social services agency is M. Luiza Coelho,HR manager for Edmonton City Centre Church Corp. in Edmonton, Alberta, Canada,. When she joined the agency last year, personnel records for 250 workers were on paper. Coelho asked her IT employee to find options for an HR system, they also did have a commercial HRIS like one employees use open-source payroll software from TimeTrex Payroll Services in Westhank, British Columbia, Canada, according to CEO Mike Benoit. TimeTrex offers modules for payroll, scheduling, attendance and job costing. There's a growing community of developers, whose contributions are vetted by TimeTrex. An average client has about two dozen employees, but some organizations have as many as 2,500 employees. The company makes money providing support and other services.

According to Gary Durbin, chief technology officer and a longtime HRIS developer SynchSource Inc. in Oakland, California, is developing open-source modules for various workplace applications, including HR.The modules his company is building, with three large beta-testing companies, will work on any HRIS, including commercial products. The company will derive revenue from services and support.

Open source does nothing to mitigate change management. Change management issues are software-independent. Deciding between open-source and proprietary software does not get HR professionals off the hook for doing proper due diligence, says Naomi Bloom, a strategic HR consultant and managing director of Bloom \& Wallace. "You need to evaluate open-source HR applications the same way that you evaluate commercial applications, via the scripted scenarios to test functional not and a careful look at the vendor who will support it.

\section{OPEN SOURCE HRIS and CLOUD HOSTING WITH SME'S}

One of the major grouses cited for a negative attitude towards open source adoption is the lack of professional support in the hardware and software arena when it comes to small to medium enterprises. Financially, there is a persistent reluctance to look at Information Technology as an investment rather than an expense. This outlook coupled with an aversion to invest in personnel to man IT infrastructure has straight jacketed organizations and limited their growth.

With the availability of cloud computing and cloud hosting services like Amazon EC2, Rackspace and other providers, web based applications can now utilize the IT infrastructure scalability that cloud hosting provides.

Cloud hosting provides a win-win situation to the SME who gets a cost effective infrastructure solution where the investment to purchase server hardware, internet bandwidth and hardware upgrades is eliminated. Couple this service along with a open source HRIS like Time Trex or OrangeHrm will provide the ideal combination.

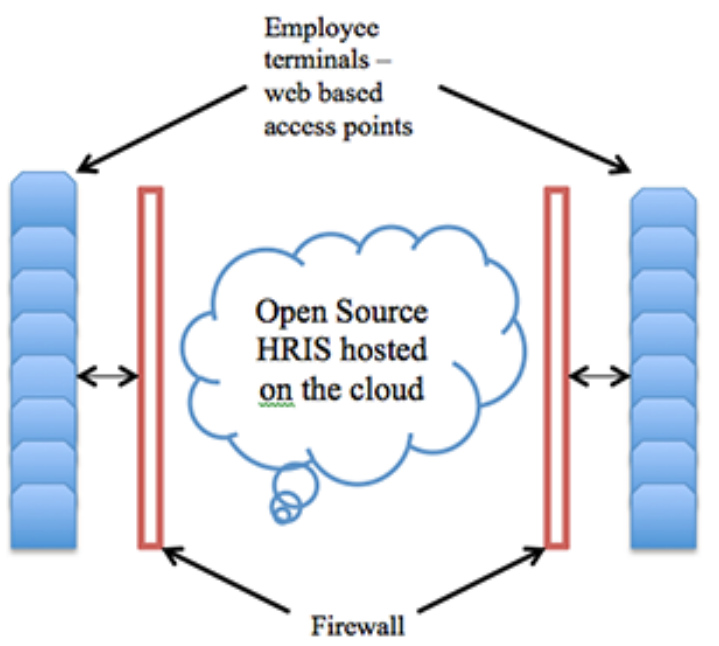

Figure No.3: Diagram representation of a generic cloud hosting service

For instance, when an organization adopts an HRIS they would most certainly invest in a server and a backup solution based on the number of user/employees in the organization. When the organization scales up in terms of number of employees, the demand on the server will increase proportionality to the number of new employees in the system thus consuming more system resources creating resource bottlenecks thus resulting in performance issues. Consider, an organization invests in scaling and upgrading the servers thus mitigating the performance issues. Over time, circumstances make compel the organization to scale down on the number of employees as part of a restructuring program or business process re-engineering thus rendering the server infrastructure which was upgraded to being under utilized. Cloud computing and hosting services provide the organization with the flexibility to upscale and downscale on resource requirements based on a need only basis thus bringing tremendous cost driven value to it IT expenditure.

\section{CONCLUSION}

Thus the paper highlights the use and importance of an Open Source Software for Human Resource Information Systems. Open source software development projects are Internet-based communities of software developers who voluntarily collaborate to develop software that they or their workplace may require.. This makes open source software projects important as research sites for many types of studies. The mind map of Open Source Model for Human Resource 
Information Systems and a Model of Adoption of an Open Source Human Resource Information System gives a good grounding in the area of open source human resource. The various opens source software in the area on Human Resources gives the reader the various features and modules that exist . It also vividly highlights the important aspect of open source HRIS and cloud hosting with SMEs.

\section{LIMITATIONS OF OPEN SOURCE}

In contrast, there is no commercial market for open source software--because its developers make it freely available as a public good. This eliminates manufactures' direct path to appropriating returns from private investment and developing source products, and so often eliminates their incentive to innovate behavior. The number of open source programmers as a percentage of the whole is small.The problem, however, is that open source must rely on the willingness of programmers to contribute code without financial compensation. Open source packages do not come with phone support or mail support. Nevertheless, there are commercial service providers who will provide support. If one needs a lot of support, consider whether the overall costs of using an opensource product will be higher than that of a proprietary product. There are fewer choices available for open source software. This type of software is being modified on an ongoing basis in the open source world, which can make it difficult to ensure that the software is compatible with other applications. Such software also does not come with a warranty, as there is no single company backing the product. Another major limitation is the quality control. Opensource projects only rely on the community criticism. It is very important to develop projects properly, as well as testing of their quality. The community criticism is sometimes incapable to identify faults in the architecture. In addition, it is also inefficient in finding imperceptible faults. These are faults which do not appear very often and which cannot be easily identified in the process of code testing. Deviant project participants can make a code copy and start to distribute different products too.

\section{FUTURE RESEARCH}

Open Source Software Innovation Research open source software research projects have some access points and technical aspects that may be unfamiliar to those just beginning research in this area. Researchers considering a first empirical research project this software development will find it useful to begin by browsing Source-forge.net to become familiar with standard project infrastructures such as code listings and mailing lists and logs devoted to different specialized functions. Much of the activity transpiring open source software projects is in the public domain.

A few areas of future research:

1. Adoption of open source HRIS is growing and one of the key drivers will be its accessibility and affordability due to software as a service (Saas) and cloud hosting.

2. Compare and contrast open source HRIS with proprietary HRIS in terms of ROI and effectiveness.

3. Impact of HRIS integration with human resource accounting systems and ERP.

4. Value creation in implementation of HRIS applications across various device platforms like tablets, cellphones and other mobile computing devices.

\section{REFERENCES}

[1] Tanenbaum, Andrew S., et al. 1990.Experiences with the Amoeba distributed operating system." Communications of the ACM 33.12 46-63.

[2] Stallman, R. (1998). Why free software is better than open source. Free software, free society: Selected essays of Richard M. Stallman, 55-60.

[3] Lakhani, K., \& Wolf, R. 2003. Why hackers do what they do: Understanding motivation and effort in free/open source software projects.

[4] Dedrick, J., \& West, J. 2003. Why firms adopt open source platforms: a grounded theory of innovation and standards adoption. In Proceedings of the workshop on standard making: A critical research frontier for information systems (pp. 236-257). Seattle, WA.

[5] Ruël, H., Bondarouk, T. V., \& Looise, J. C. 2004. EHRM--Innovation Or Irritation?: An Exploration of Web-based Human Resource Management in Large Companies. Utrecht: Lemma Publishers.

[6] Yusoff, Y. M., Ramayah, T., \& Ibrahim, H. 2010. EHRM: A proposed model based on technology acceptance model. Afr. J. Bus. Manage, 4(13), 30393045 .

[7] Chau, P. Y., \& Tam, K. Y. 1997. Factors affecting the adoption of open systems: an exploratory study Management Information Systems Quarterly, 21, 1-24.

[8] Koch, M. J., \& McGRATH, R. I. T. A. 1998. Improving labor productivity: Human resource management policies do matter. Strategic Management Journal, 17(5), 335354.

[9] Von Hippel, E., \& Von Krogh, G. 2003. Open source software and the "private-collective" innovation model: Issues for organization science. Organization science, 14(2), 209-223

[10] Von Krogh, G., \& von Hippel, E. 2006. The promise of research on open source software. Management Science, 52(7), 975-983

[11] Hubbard, J. C., Forcht, K. A., \& Thomas, D. S. 1998. Human resource information systems: An overview of current ethical and legal issues. Journal of Business Ethics, 17(12), 1319-1323.

[12] Faldetta, G. 2002. The content of freedom in resources: The open source model. Journal of Business Ethics, 39(1), 179-188.

[13] Hars, A., \& Ou, S. (2001. Working for free? Motivations of participating in open source projects. In System Sciences, 2001. Proceedings of the 34th Annual Hawaii International Conference .

[14] Roberts, B. 2009. HR Technology-Open-Source Solutions for HR-Faced with tightening technology budgets, some HR professionals are finding solutions in open-source software. HR Magazine, 54(3), 69.

\section{Website References}

http://www.itbusiness.ca/

http://eu.conecta.it/paper/

http://opensource.org/ 
International Journal of Computer Applications (0975 - 8887)

Volume 61-No.8, January 2013

http://en.wikipedia.org/wiki/Open_source

http://www.gnu.org/

http://www.openbravo.com/

http://eu.conecta.it/paper/

http://www.orangehrm.com

http://waypointhr.com

http://www.openapplicant.org

http://sourceforge.net http://www.timetrex.com

http://source.android.com/

http://www.businessenterprisecentre.ca/

http://openhris.com/

http://www.ontariocanada.com/

http://www.synchr.com/

http://www.shrm.org/ 